\title{
El mito del progreso en la literatura: \\ escuela y migración en dos novelas indigenistas
}

\section{Daniel Carrillo Jara}

Universidad Científica del Sur

Centro de Estudios Culturales y Literarios

dcarrillojara@gmail.com

\section{RESUMEN}

El objetivo de este artículo es demostrar cómo se articula el mito del progreso en dos novelas indigenistas. El análisis de El mundo es ancho y ajeno (1941), de Ciro Alegría, y Todas las sangres (1964), de José María Arguedas, permite explorar la representación de dos hechos vinculados al progreso en la zona andina: la escuela y la migración. De esta forma, es posible afirmar que estos autores conciben de manera distinta la modernización andina.

\section{PALABRAS CLAVE}

Progreso, escuela, migración, indigenismo.

\section{ABSTRACT}

The aim of this paper is to demonstrate the articulation of the myth of development in two indigenist novels. Analysis of El mundo es ancho y ajeno (1941) by Ciro Alegría and Todas las sangres (1964) by José María Arguedas lets explore the representation of two factors linked to development in the Andean region: school and migration. Thus, it can be said that these authors conceive differently Andean modernization.

\section{KEY WORDS}

Development, school, migration, indigenism.

Es indudable que, durante siglos, las comunidades campesinas de la zona andina se han visto acorraladas por políticas sociales que negaban e intentaban destruir su cultura. Rodrigo Montoya explica que este proceso se ha realizado mediante la reducción de toda una sociedad y cultura a 
un estereotipo determinado ${ }^{1}$ : entre los siglos XVI y XVIII, los «indios paganos» debían ser cristianizados a través del bautismo y la extirpación de idolatrías; durante el siglo XIX hasta aproximadamente 1940, los «indios salvajes» debían acudir a la escuela para convertirse en «personas civilizadas»; por último, en las últimas décadas, los «indios tradicionales» deben modernizarse mediante el acceso a los medios de comunicación, como la televisión y el internet. Sin embargo, es también evidente que, a pesar de la violencia de esos mecanismos de aculturación, la cultura andina ha sido lo suficientemente flexible para seleccionar lo beneficioso de los otros, así como para conservar lo útil de su propio universo cultural.

Es necesario recordar lo anterior, ya que de esa forma se evita cometer dos errores importantes que han sido definidos por Carlos Iván Degregori como la visión romántica y antirromántica sobre las poblaciones andinas ${ }^{2}$ : la primera de ellas percibe a esas comunidades como culturas inalterables a lo largo del tiempo, petrificadas en su autenticidad; en cambio, la segunda defiende su inserción en la cultura occidental, es decir, la aculturación o la pérdida total de sus rasgos culturales para así modernizarse. Ambas tendencias son equivocadas, ya que reducen el complejo proceso de modernización a una sola arista del problema: el sujeto andino se encierra en su propia cultura o se acopla completamente en lo occidental.

Esas dos perspectivas también resultan erróneas por su concepción de la población andina como una sociedad pasiva ante los embates de la modernización. En realidad, tuvo una participación mucho más activa en su búsqueda de la inclusión en la sociedad peruana: «Lo cierto es que el tránsito del mito de Inkarrí al mito del progreso reorienta en 180 grados a las poblaciones andinas, que dejan de mirar hacia el pasado. Ya no esperan más al inka, son el nuevo inka en movimiento. El campesinado indígena se lanza entonces con una vitalidad insospechada a la conquista del futuro y del "progreso"» ${ }^{3}$. Para el antropólogo peruano, esta búsqueda del progreso tiene como consecuencia una serie de actos que implican el reclamo político por los derechos nunca respetados. El mito del progreso se constituye entonces como un proceso que necesariamente deviene en «un conjunto de movilizaciones, movimientos sociales, el más importante de los cuales posiblemente sea el de la lucha campesina por la tierra, seguido muy de cerca por la lucha campesina por la educación, que se ha subestimado mucho [...]. En tercer lugar, no en orden jerárquico sino simplemente secuencial, [...] las grandes migraciones y las luchas de los migrantes en las ciudades» ${ }^{4}$.

1 Montoya 1990: 89.

2 Degregori 2013b: 298.

3 Degregori 2013a: 220.

4 Degregori 2013b: 296. 
El propósito de este artículo es demostrar que el mito del progreso no constituye solo un hecho verificable en la realidad social, sino que también se manifiesta en la literatura indigenista. Es preciso aclarar, sin embargo, que nuestro objetivo no es una lectura sociológica de los textos que contraste los hechos narrados con los hechos históricos; en ese sentido, coincidimos con la afirmación de Dorian Espezúa ${ }^{5}$ acerca de la narrativa de Arguedas:

Está demostrado lo erróneo que es realizar una lectura de TLS [Todas las sangres] tratando de hacer coincidir uno a uno los elementos que conforman la novela con los elementos de la realidad peruana. Hay que considerar que estamos frente a una novela y no frente a un testimonio o un documento sociológico. En consecuencia, el estatuto ficcional de la narrativa arguediana en TLS se circunscribe a lo analógico verosímil y no a lo homológico verdadero.

Nuestra intención, por lo tanto, es demostrar que el mito del progreso se expresa de manera particular en dos novelas indigenistas, El mundo es ancho y ajeno (1941), de Ciro Alegría, y Todas las sangres (1964), de José María Arguedas, y que la lectura de ambos textos permite también una mejor comprensión de la realidad social. Nos interesa así determinar cómo se representan dos hechos vinculados a la idea del progreso: la escuela y la migración; ese análisis nos permitirá afirmar que ambos autores conciben la modernización andina de formas distintas.

\section{La escuela: un derecho nunca cumplido}

Los científicos sociales han demostrado que las exigencias por el acceso a la escuela siempre conllevan una cierta ambigüedad: si por un lado el acceso a la letra y al conocimiento occidental funciona como un arma que el campesino puede emplear para defenderse de los abusos; por el otro, también puede constituir una forma de aculturar a una sociedad.

Para el primer caso, Montoya ha demostrado que la educación es relacionada metafóricamente con «abrir los ojos» o «despertar»: «No saber leer y escribir equivale a no tener ojos o estar con los ojos cerrados. [...] Los padres envían a sus hijos e hijas a la escuela para que "despierten" -ikchanankupaq - y para que "abran los ojos" —ñawinkunata kichanankupaq—»; sin embargo, el propio autor reconoce el carácter contradictorio de la escuela, ya que también sirve como un instrumento de dominación: 
El sistema escolar oficial del Perú de hoy combate las culturas de los grupos étnicos, impone el castellano, proscribe a las otras lenguas, castiga y sanciona a los niños que provienen de los diversos grupos étnicos por hablar y escribir mal una lengua que no es la suya, ignora las religiones y el saber de esos grupos porque impone lo occidental y cristiano considerado etnocéntricamente como lo único bueno y verdadero ${ }^{7}$.

En las dos novelas indigenistas, el rasgo contradictorio de la educación se ha minimizado para remarcar así su carácter liberador y la posibilidad de servir como instrumento que permita, por fin, la reivindicación social: «De todos modos — volvió a sonar la voz prudente - , son avances, son avances... Demos gracia a que estos — el indiferente volvió a ser señalado— no saben leer ni se enteran de nada; si no ya los vería usted... ya los vería.... ${ }^{8}$; «Si aprenden a leer, ¿qué no querrán hacer y pedir esos animales» ${ }^{9}$. A pesar de esa coincidencia, es evidente que el tema de la escuela se desarrolla más ampliamente en El mundo es ancho y ajeno; por ejemplo, en esta novela el vínculo entre la educación y la liberación social no solo se expresa mediante el temor del hacendado o el poderoso, sino también a través del deseo de los campesinos: «Convenía que los muchachos supieran leer y escribir y también lo que le habían dicho que eran las importantes cuatro reglas. Rosendo - qué iba a hacer - contaba por pares, con los dedos si era poco y con piedras o granos de maíz si era mucho, y así todavía se le embrollaba la cabeza en algunas ocasiones de resta y repartición. Bueno era saber» ${ }^{10}$.

Como ya ha demostrado Tomás Escajadillo, en la novela de Ciro Alegría claramente se quiere comparar dos aspectos de la construcción del ámbito educativo: «Es innegable la intencionalidad del texto de contrastar el aspecto material de la "construcción" — que marcha magníficamente bien- con el otro conflictivo aspecto, relativo a las gestiones, trámites y papeleo» ${ }^{11}$. A este abandono estatal se suma la dificultad para encontrar un profesor: «El alcalde fue donde el hijo del escribano a comunicárselo y él le dijo: ¿Así que era en serio lo de la escuela? Yo creí que bromeabas. No voy a lidiar con indiecitos de cabeza cerrada por menos de cincuenta soles". Maqui quedó en contestarle, pues ya había informado de que

7 Montoya 1990: 105-106. Incluso, Ansión cuestiona, a partir de la convulsionada década de 1990, la posibilidad de que la escuela todavía se vincule con el mito del progreso: «Deterioro extremo tanto material como pedagógico, violencia política. Estas son las dos condiciones fundamentales que han puesto a prueba la supervivencia del mito educativo como mito movilizador» (1993: 8).

8 Alegría 2002: 17.

9 Arguedas 2001: 71.

10 Alegría 2002: 16.

11 Escajadillo 1978: 25. 
cobraba treinta soles» ${ }^{12}$. En realidad, estas trabas eran cosa común (aún lo son en la actualidad), por lo que el sistema educativo para los sectores rurales dependía básicamente de los aportes de los padres tanto en materiales como en trabajo ${ }^{13}$.

Mucho más importante que la construcción de la escuela es la función que en el imaginario del campesino desarrollará la educación. En la novela, la edificación del edificio escolar se inicia durante la alcaldía de Rosendo Maqui (en los primeros tres capítulos del libro y es una tarea que nunca llegará a su fin); pero la construcción ideológica se realiza con la llegada de Benito Castro y su ascenso a alcalde de la comunidad. Es decir, el narrador formula una definición de la escuela y sus objetivos solo en los últimos capítulos de la novela, cuando Castro es alcalde Rumi. En esta definición el ámbito educativo es claramente vinculado con el abandono de las supersticiones y el progreso.

Para entender esos vínculos, es necesario recordar que luego de haber perdido sus tierras y haberse desplazado a Yanañahui, Rumi se encuentra en un estado calamitoso; por lo que Benito Castro desea desaguar la laguna para así tener mejores tierras para el cultivo y mudar el pueblo hacia unas ruinas cercanas, porque son el único lugar protegido de los fuertes vientos. Sin embargo, muchos comuneros se oponen, debido a la creencia en una mujer que protege a la laguna y en el Chacho, una suerte de demonio. En cambio, para Castro, se trata solo de supersticiones que impiden la modernización de la comunidad: «De funcionar escuela en Yanañahui, en diez o veinte años nadie creería en lagunas encantadas y Chachos. Por no ser supersticiosos, los hacendados trabajaban mejor, plantando la barreta donde creían conveniente. Pero no se podía esperar diez ni veinte años» ${ }^{14}$. Es evidente, entonces, que los planes de Castro constituyen un proyecto modernizador en dos sentidos: en primer lugar, moderniza la comunidad al ampliar las tierras fértiles para el cultivo y buscar mejores zonas de asentamiento; $y$, en segundo lugar, también se trata de una modernización ideológica que exige, como paso previo a la modernización económica, abandonar las creencias tradicionales.

En ese segundo plano se vincula el abandono de las supersticiones con el proyecto escolar: «[...] Cuando el buen viejo Rosendo quiso una escuela fue sin duda porque intuyó el mundo al cual no tenían acceso. Pero ahora era preciso comenzar desde otro lado. La escuela habría realizado su labor en diez o veinte años. No se podía esperar tanto si la vida era 
miserable» ${ }^{15}$. Benito Castro vincula, entonces, la renovación ideológica con el proyecto educativo de Rosendo Maqui; sin embargo, el contraste se origina en la velocidad de la modernización: el tiempo exige que se realice lo antes posible. La escuela constituye, por lo tanto, una esperanza para el futuro, ya sea porque Rosendo Maqui no puede conseguir los implementos necesarios para el establecimiento del colegio o porque Benito Castro comprende la urgencia de un cambio ideológico que permita a la comunidad sobrevivir en las nuevas condiciones.

De forma similar a la novela de Ciro Alegría, en Todas las sangres el aparato estatal impide la conformación de la escuela: «El inspector escolar y el gobierno no accedieron a la solicitud de los indios que solo pidieron una maestra para Lahuaymarca, porque la comunidad construyó un local risueño, con ventanas grandes y un jardín [...]» ${ }^{16}$. Sin embargo, es necesario precisar que el mito de la escuela está menos desarrollado, y la educación se vincula directamente con el acceso a la lectura y escritura del castellano.

En el célebre pasaje en el que se narra las desventuras de Rendón Willka en la escuela de San Pedro, se nos remarca que los principales instrumentos del escolar son el silabario, los cuadernos y el pizarrín: todos ellos vinculados a la letra. Además, Rendón es acosado violenta y constantemente, debido a su particular uso del idioma: «Lee en quechua, animal. ¿No ves que no sabes castellano? "A, Bi, Ci...." Se dice $\mathrm{Be}, \mathrm{Ce}{ }^{17}$. En realidad, nos atrevemos a sugerir que en Todas las sangres debe hablarse menos de un mito de la escuela que de un mito del idioma, ya que la mayor cantidad de referencias al aprendizaje giran en torno al hecho de acceder a la tecnología escritural y no al colegio en sí mismo. Este hecho se confirma si se percibe que la escuela es tan accesoria que es posible aprender a leer y a escribir fuera de ella: «Después que los vecinos los expulsaron de la escuela, él siguió deletreando en su librito escolar; no dejó de escribir con un lápiz las mismas frases y aun logró agregar otras palabras del castellano que aprendió después» ${ }^{18}$; «En la cárcel vas a aprender a leer. ¡Que te lleven a Lima!»» ${ }^{19}$.

15 Alegría 2002: 519.

16 Arguedas 2001: 71 y 73. Es lamentable que, en la década de 1990 (e incluso en la actualidad), persistieran estas condiciones de abandono estatal: «[...] esa modernidad se niega a recibirlos, les cierra los canales de ascenso, los maltrata y los olvida. Aunque el término ha sido ya bastante usado, los convierte en verdaderos"marginales"» (Ansión 1993: 17).

17 Resulta tentador homologar esa representación del colegio con la idea de que «la escuela es un arma formidable en el Perú para enfrentar y destruir las culturas de todos los grupos étnicos sometidos [...]» (Montoya 1990: 104); pero lo cierto es que en la novela se explica que el maltrato que sufre Rendón es consecuencia de propósito más particulares: «¡a no, papá! ¡Ya no! [...] ¡Ustedes, ustedes me dijeron que lo ofendiera, que lo fregara todos los días! ¡Ustedes, pues, papá!» (Arguedas 2001: 77).

18 Arguedas 2001: 71.

19 Arguedas 2001: 393. 
Con respecto a lo anterior, en la novela se plantean dos perspectivas respecto al sujeto andino que ha accedido a la letra: en primer lugar, los hacendados y los poderosos critican el surgimiento de un nuevo sujeto cuyo conocimiento de la escritura lo ha alienado completamente: «Y ahora ha surgido un personaje peor, intratable, con empuje de demonio: el mestizo leído y el indio leído. Odian y trabajan por odio» ${ }^{20}$. Por otro lado, se encuentra el individuo que comprende los usos del castellano, pero que no ha renegado de sí mismo y cuya máxima podría ser la siguiente: «Yo comunero leído; siempre, pues, comunero» ${ }^{21}$. En cierta forma, este contraste niega la idea que se mencionó anteriormente: así como arma de liberación, la escuela también funciona como instrumento aculturador. Carlos Iván Degregori'22 ya había remarcado que la escuela no siempre constituye un elemento opresor ${ }^{23}$ :

La «apropiación» de los instrumentos de dominación los lleva ciertamente a asemejarse a los dominadores, pero esa semejanza no es necesariamente sinónima de «aculturación», de abandono de lo propio y aceptación acrítica de lo dominante. La vitalidad de algunas manifestaciones de la cultura andina, incluso en las ciudades, relativiza el pesimismo respecto a su capacidad para enfrentar el mundo contemporáneo.

A diferencia de El mundo es ancho y ajeno, resulta difícil afirmar que la escuela es identificada con la modernización en la novela de Arguedas. Aunque esa sí es la visión de los sujetos hegemónicos (gamonales, hacendados, etc.): «Les pondremos escuelas. Que no aprendan a la guerra a la civilización, sino ordenadamente» ${ }^{24}$; lo cierto es que el sujeto andino en Todas las sangres no accede a la escuela (o a la escritura) en busca de una renovación ideológica, como proyectaba Benito Castro al homologar educación y abandono de antiguas creencias. Por el contrario, el sujeto se apropia del conocimiento occidental para afirmar una nueva identidad vinculada directamente con el mundo andino $y$, por lo tanto, plantea una forma particular de modernidad ${ }^{25}$. En cualquiera de los dos casos, la educación constituye un mecanismo importante de lucha y reivindicación social, por lo que se vincula directamente con el mito del progreso:

20 Arguedas 2001: 383-384. Definitivamente, esta afirmación hace eco de los planteamientos de López Albújar: «Una vez que ha aprendido a leer y escribir, menosprecia y explota a su raza. Indio letrado, indio renegado» (1987: 17).

21 Arguedas 2001: 38.

22 Degregori 1991: 8.

23 Por el contrario, Rodrigo Montoya afirma de manera pesimista lo siguiente: «Dentro de la lógica del pensamiento quechua, es evidente que la escuela es vista como un elemento extraño, ajeno, pero inevitable y necesario» (1990: 108).

24 Arguedas 2001: 444.

25 Desarrollaremos este planteamiento más minuciosamente en el siguiente apartado. 
El llamado mito de la educación formó parte de un imaginario mucho más amplio que movilizó a grandes sectores campesinos-andinos: el mito del progreso, que traía su propia simbología y que tuvo la capacidad de modificar totalmente la faz de nuestro país. Este mito, en sus vertientes más tradicionales (ascender dentro de una jerarquía ya dada) y progresistas (modificar el entorno social o abrir nuevos espacios, colectivos o individuales) se hizo fuerza material en la práctica de miles y miles de personas, y se hizo tejido social y «sociedad» en lo que estas personas fueron construyendo a lo largo de más de tres décadas ${ }^{26}$.

\section{La migración: cambios sociales y culturales}

Denominamos migración a todo desplazamiento geográfico, de un sujeto individual o grupos sociales, asociado usualmente a causas económicas y sociales. En el particular caso de la migración en el Perú (cuya dinámica se acrecienta a partir de 1950), este proceso es el resultado del

hecho de que la política económica de los Estados no permitía en el campo un desarrollo de la capacidad de producción de acuerdo con las necesidades de las poblaciones crecientes, pero además y sobre todo era un resultado de expectativas crecientes entre la población que no seguían manteniendo las restricciones de un movimiento territorial que les había impuesto el sistema colonial ${ }^{27}$.

Es posible afirmar que la sociedad peruana en su totalidad se ve reconstituida en su estructura aproximadamente desde 1950: los sistemas culturales que se habían mantenido distanciados (el sistema cultural criollo y andino) inician una vertiginosa serie de encuentros y desencuentros que resultará en una totalidad caracterizada por el conflicto. Es importante recordar que la década de 1950 es una fecha clave, ya que constituye el periodo en que la migración hacia Lima se intensifica.

Por otro lado, Antonio Cornejo Polar está interesado en cómo el proceso migratorio influye en la configuración de la identidad; por esa razón, establece la categoría de sujeto migrante: un sujeto plural que asume experiencias distintas, culturas diversas, tiempos y lugares discontinuos. Este sujeto no solo es plural, también constituye un ser fragmentado, disgregado, desestabilizado, inestable, ya que, en ese juego de oposiciones, el migrante «ni puede ni quiere fundirlas porque su naturaleza discontinua pone énfasis precisamente en la múltiple diversidad de esos tiempo y de esos espacios y en los valores o defectividades de los unos y los otros» ${ }^{28}$.

26 Ansión 1993: 17.

27 Golte 2001: 117-118.

28 Cornejo Polar 1995: 102. 
Es un sujeto que, por lo tanto, reside, experimenta y construye desde un «entre-culturas» o desde la frontera.

En el caso de El mundo es ancho y ajeno, la migración se representa a través de dos núcleos temáticos: los comuneros emigrados y la figura de Benito Castro. El primero ha sido ampliamente desarrollado por Tomás Escajadillo; por esa razón, nos centraremos en el segundo. Sin embargo, nos parece pertinente desarrollar brevemente los planteamientos del crítico peruano. Para el autor, la novela de Ciro Alegría desarrolla como idea fundamental una propuesta que puede resumirse en dos enunciados: «La comunidad es el único lugar habitable» $\mathrm{O}$ «Mi comunidad es mejor» ${ }^{29}$. Por esa razón, los cinco episodios correspondientes a los comuneros emigrados cumplen una doble función: «La función interpolativa de estos hilos narrativos es muy clara, como lo es, por otro lado, su función de destacar, mediante el proceso acumulativo del contraste y la antítesis la "idea central" de la novela ${ }^{30}$. Es decir, cada uno de esos capítulos tiene como objetivo, por un lado, dilatar el desarrollo de la trama central de la novela (crear suspenso); y, por el otro, crear un vívido contraste entre la vida de la comunidad y las penurias de los emigrados: Amadeo Illas es explotado brutalmente en un sembrío de coca, Calixto Páucar muere durante una huelga en un asiento minero, Augusto Maqui queda ciego mientras trabaja como cauchero, Juan Medrano carga con una vida miserable en la hacienda Solma y Demetrio Sumallacta se emborracha al no encontrar su lugar en el mundo (los dos últimos episodios son ciertamente menos violentos que los anteriores).

Los dos núcleos temáticos coinciden en las constantes comparaciones que establecen Benito Castro y los comuneros emigrados entre su realidad actual y la comunidad: «Sin embargo, era dulce pensar en la vuelta» ${ }^{31}$; «iY qué diferencia entre el trabajo realizado en las haciendas y el trabajo realizado en la comunidad!» «2; «iAh, sí, se parece a mi comunidá, pero mi comunidá es mejor» ${ }^{33}$. No olvidemos, por cierto, que para Cornejo Polar el recuerdo de la comunidad es un elemento importante del sujeto migrante: «Migrar es nostalgiar» ${ }^{34}$. Sin embargo, es importante también la diferencia que establece Escajadillo entre los personajes: «Benito no es un "comunero emigrado" por voluntad propia, sino "comunero errante" que está separado temporalmente — por largo tiempo, es verdad-del seno 
de la comunidad [...]. Benito no está huyendo de la mala vida en las peñolerías de Yanañahui, Benito no está huyendo de la comunidad, está esperando que corra el plazo para poder volver a ella» ${ }^{35}$. Este planteamiento nos parece relevante, porque implica una diferencia sustancial entre el protagonista de la historia y aquel «migrante [que] es expulsado por las condiciones económicas existentes de su lugar y no tiene mucho margen de maniobra: si no sale, se muere de hambre ${ }^{36}$, y explica la diferente importancia que ambos núcleos temáticos adquieren en la novela.

Mientras que el ciclo de los comuneros emigrados constituye un conjunto de historias para contrastar la idea central de la novela, la historia de Benito Castro se engarza con la trama principal. Esta diferencia se establece principalmente porque el viaje de Benito Castro se caracteriza por un aprendizaje vinculado tanto a la política como a la letra; ambos tipos de aprendizaje son consecuencia de su establecimiento en Lima y de su amistad con Lorenzo Medina ${ }^{37}$. Sin embargo, para Castro es mucho más importante el conocimiento de la letra que el conocimiento político: «Ahora volveré sabiendo leer. ¿Quieres repasarme la lección? No creas que desoigo todo lo que hablas, pero, a lo mejor, si te acepto mucho, me metes en cosa que no convenga... Yo quiero volver a mi comunidá. [...] A veces me ha dao vueltas la cabeza y mi ignorancia me causó mucha pena.... ${ }^{38}$. De esta forma, es totalmente coherente que, al regresar a Rumi, una de las primeras acciones de Benito Castro sea leer una carta a la joven Cashe y su madre. No olvidemos que en la novela se establece un claro vínculo entre la migración y el acceso a la letra: «[...] tu modo de ser hombre y po conocer el mundo y las letras $»^{39}$.

Es evidente entonces que Benito Castro se diferencia de los comuneros emigrados en que realmente constituye un sujeto migrante, ya que se configura como un sujeto dividido entre su presente en otras regiones y sus constantes recuerdos de Rumi, y porque sus viajes le han permitido dominar ciertas instrumentos del otro sistema cultural (la escritura). En El mundo es ancho y ajeno, este personaje, al igual que la escuela, es identificado con el proceso modernizador de la comunidad ${ }^{40}$. En el apartado anterior identificamos que la escuela se vincula con el abandono de las supersticiones; pero, en el debate que se genera cuando Castro desea

35 Escajadillo 1977: 138

36 Degregori 2013b: 305.

37 Alegría 2002: 445-461.

38 Alegría 2002: 459.

39 Alegría 2002: 517.

40 De alguna forma, Tomás Escajadillo intuyó esta relación, pero no la desarrolló plenamente: «¿Se insinúa que el background limeño resulta necesario para dirigir una comunidad en emergencia a cambios trascendentes?» (1977: 141). 
desaguar la laguna y movilizar Rumi hacia las ruinas, también es posible identificar otras relaciones: "Sus partidarios, esos locos y malos comuneros, entre los cuales casi todos eran foráneos, decían que buscaban el progreso. ¡Progreso! El indio no debía imitar al blanco en nada porque el blanco, con todo su progreso, no era feliz» ${ }^{41}$.

De la misma forma que con la escuela, en la novela se vincula claramente a Benito Castro, sujeto migrante, conocedor de la escritura, con la modernización. Es evidente que la razón fundamental de esta relación es el hecho de que haya viajado y accedido a la letra, pero no haya olvidado el amor por su comunidad. Por eso, regresa e inicia una época de progreso en Rumi. Eso se hace aún más evidente en la doble filiación cultural del último alcalde (su apego por la tierra y la agricultura, pero su abandono de las supersticiones) que contrasta con «el indio duro de siempre, reacio a todo innovación, oscuramente empecinado» ${ }^{42} y$, especialmente, un obstáculo a la modernización de la comunidad.

La migración es representada en toda su complejidad en Todas las sangres. Incluso, nos parece acertado afirmar que, a pesar de que la categoría de sujeto migrante fue planteada por Cornejo Polar para el análisis de la narrativa de Arguedas, ese concepto resulta insuficiente para explicar esta novela. Esto se debe a que el planteamiento del crítico arequipeño vincula directamente la migración con la aparición de un sujeto dividido entre dos culturales y con la capacidad de dominar elementos de ambos sistemas $^{43}$, como si ese fuera el único resultado posible del proceso migratorio. En cambio, en la novela de Arguedas es fácil distinguir una serie de matices en el sujeto migrante, es decir, es posible reconocer distintos sujetos que son producto de la migración:

Hombres y mujeres trataban de asimilar rápidamente los modales ciudadanos; aprendían los bailes de moda y a usar los trajes y peinados impuestos por la influencia norteamericana. La mayor parte de estos emigrados exageraba los nuevos usos de la ciudad, y la forma como danzaban los bailes de moda; procurando demostrar que los dominaban, daban a la apretada concurrencia de los salones alquilados un aspecto entre grotesco y triste para el espectador sensible. Era evidente que muchas de las parejas no se divertían, sino que simulaban; padecían tratando de retorcerse, de seguir el compás endiablado o muy lento de los bailes "afrocubanos» o "afroyanquis». En sus músculos seguían aún rigiendo "la pesadez" del habitante andino, duro de cuerpo, por la práctica de subir y bajar inmensas cuestas y

41 Alegría 2002: 523. 
respirar el aire de las grandes alturas. ¡Por fin! Como despedida de la fiesta se tocaban huayno o pasacalles. Entonces se lanzaban a bailar como presos recién liberados, muchas parejas, y gozaban; otras, especialmente por parte de las muchachas bailaban como desanimadas, porque procuraban demostrar que ya estaban totalmente «deserranizados» y que habían olvidado el huayno, y no faltaban hombres y mujeres que no salían a bailar las danzas de sus pueblos declarando en voz alta que se habían olvidado de ellas. Y de verdad, muchos de estos jóvenes no podían bailar; la vergüenza los estorbaba; eran los mismos que se negaban a hablar el quechua y que padecían mientras intentaban bailar con la mayor «destreza» los bailes extranjeros ${ }^{44}$.

Es notable cómo Arguedas pudo representar, en esta escena sobre una fiesta en un club departamental, las diferentes formas de interculturalidad que son producto del proceso migratorio ${ }^{45}$. Desde los sujetos aculturados, que rápidamente olvidan la cultura de origen para asimilar la cultura hegemónica («estos emigrados exageraban los nuevos usos de la ciudad, y la forma como danzaban los bailes de moda; procurando demostrar que los dominaban, daban [...] un aspecto entre grotesco y triste»), hasta aquellos que rechazan lo urbano para refugiarse en la cultura que dejaron atrás («se tocaban huayno o pasacalles. Entonces se lanzaban a bailar como presos recién liberados, muchas parejas, y gozaban»).

La construcción de la identidad y su vínculo con la migración es justamente uno de los grandes temas de la novela. Recordemos que uno de los tópicos del indigenismo es la visión crítica de la ciudad, porque irremediablemente corrompe al sujeto andino; en cambio, Arguedas logra escapar de esa dicotomía. De la misma forma en que la escuela no es necesariamente un instrumento de dominación y aculturación, el autor propone que es posible reaccionar de dos formas opuestas luego de migrar a Lima, y esto se representa mediante dos personajes: Perico Bellido y Rendón Willka. El primero de ellos ha estudiado Contabilidad en Lima y ha regresado al pueblo de San Pedro, pero se ha «contaminado» de las formas de occidentales:

44 Arguedas 2001: 427-428.

45 Estos diferentes sujetos que constituyen un resultado de la migración también pueden ser explicados por las dos modalidades por las que el migrante ingresa a la ciudad: «Hasta hace dos o tres décadas el migrante típico llegaba solo a la capital. Tenía que buscar sus medios de vida por sí mismo, o bien [...] era recibido por un conocido o pariente lejano [...]. Para integrarse al medio, debía asumir patrones de comportamiento ajenos [...]. Posteriormente, en especial durante las últimas dos décadas, la llegada masiva de migrantes permite la generalización de los "clubes de residentes"y de todo un ambiente provinciano que — más allá del club- acoge al recién llegado. [...] Así, el desarraigo no será tan grande y podrá conservar partes importantes de sí mismo en su integración a la vida en la capital» (Oliart 1984: 73-74). 
En la tienda de Asunta [Perico] encontró a dos señores y tres jóvenes. Los saludó muy galantemente y pretendió besar la mano de Asunta.

—Eso no se acostumbra aquí, Perico —le dijo ella.

- Tampoco en Lima - afirmó uno de los jóvenes.

—En Francia y Norteamérica es costumbre — respondió Bellido ${ }^{46}$.

Estas diferencias son evidentes también por su forma de vestir: "Se protegía el cuello con un pañuelo de seda ornado de frases graciosas, de aviones y paisajes con bisontes» ${ }^{47}$; sin embargo, esas particularidades, que Perico cree notables y dignas de elogio, son en realidad incongruentes en la zona andina. Es decir, los signos de la otra cultura, ostentados de esa forma, ocasionan el rechazo en la cultura de origen: «Tú no sirves ya para San Pedro. Te ves en el espejo y crees que te vamos a recibir como un "extranjero elegante". Quizás serás elegante para las limeñas, aquí o se ríen de ti o te curiosean ${ }^{48}$. Perico es, entonces, un sujeto descentrado, incongruente en cualquier cultura: rechazado en lo occidental y en lo andino; representa, por lo tanto, las peores consecuencias de la migración. Experiencia más trágica si consideramos que su padre también migró debido a que se unió forzosamente al ejército; sin embargo, representa el viaje sin cambios en la identidad: «Lo desgarraron de su pueblo, pero volvió pronto y sin cambiar. Ahora no le entendía su hijo, el contador»; por eso, no es extraño que le grite a Perico: «¡Perico! ¡Carajo! Regrésate a Lima. Eres maricón, ¿o qué?» ${ }^{49}$.

Rendón Willka también ha regresado de Lima a San Pedro; su vestimenta es asimismo motivo de conflicto en la novela:

El criado lo miró con asombro. Rendón estaba vestido de americana, con un traje grueso de lana azul. La camisa no estaba limpia. Recibió el abrazo del exindio, desconcertado aún, mirándolo cada vez más detenidamente. Se olvidó de sus señores.

-Tu ropa, tu ropa..., hermano Demetrio - le dijo con entusiasmo y extravío ${ }^{50}$.

Al principio, se asocia a Rendón con la contaminación de la ciudad: «Se ve que has venido con la insolencia que se aprende en la costa» ${ }^{51}$; sin embargo, él ha logrado apropiarse de los elementos de la otra cultura sin aculturarse: 
-Aquí desconfiamos de los indios que visten casimir.

- Hay razón, don Bellido. A cualquiera hace cojudo el casimir no estando indio. Yo con tranquilidad... [responde Rendón] ${ }^{52}$.

La vestimenta es pues una metáfora de los conflictos culturales y de identidad. Si Perico representaba la opción de los que bailaban torpemente los bailes de la ciudad (es decir, la opción de la aculturación, la pérdida de la cultura de origen, el descentramiento ontológico); no es posible afirmar que Rendón representa la opción de refugiarse culturalmente y rechazar a la otra cultura (opción de los que no bailaban y solo gozaban con los huaynos). En cambio, el protagonista del Todas las sangres simboliza la plasticidad cultural, la posibilidad transcultural de dominar los signos de dos culturas, de apropiarse de la cultura hegemónica para expresar la cultura de origen.

Es evidente entonces que la migración es un proceso sumamente complejo que no puede ser explicado cabalmente con el concepto planteado por Cornejo Polar. Por esa razón, la triple clasificación ${ }^{53}$ que propone Abril Trigo resulta más útil: el autor plantea la oposición entre el inmigrante, que constituye «una suerte de síntesis cultural, de decantamiento de experiencias, de fusión afectiva. Cuando finalmente el inmigrante resuelve las fracturas y discontinuidades entre el entonces-allá y el aquí-ahora, puede concentrarse en la praxis social sin conflictos ni resabios con el pasado» ${ }^{54}$, y el migrante, que "habita el tiempo-espacio como un hábitat móvil, porque la migrancia, en su ir y venir, siempre en tránsito, termina por disolver la identificación inalienable y certera con un espacio-tiempo particular» ${ }^{55}$. Por otro lado, también esboza la categoría de sujeto diaspórico: «[...] no se asimila a la sociedad anfitriona, resiste a la interpelación del imaginario nacional hegemónico (que quizá lo rechace), y persiste en identificarse en lo cotidiano con su comunidad minoritaria (experiencia en gueto) y vicariamente con una patria utópica (a nivel de imaginario) ${ }^{56}$. Es decir, mientras que el sujeto inmigrante puede asimilar culturas, ni el sujeto diaspórico ni el migrante lo logran; en cambio, el primero construye su espacio y cultura primigenios como una utopía, mientras el segundo se desarrolla en un «entre culturas».

52 Arguedas 2001: 57.

53 También es importante mencionar que Julio Noriega encuentra al menos tres tipos de migrantes andinos en la literatura: el que busca reconquistar la ciudad, el que permanece en una continua despedida y el que, al regresar a su hogar, se siente un desterrado en su misma tierra (Noriega 1997: 59-63).

54 Trigo 1997: 275.

55 Trigo 1997: 277.

56 Trigo 1997: 276. 
Tanto en el planteamiento de Cornejo Polar como en el de Trigo, Rendón Willka, de la misma forma que Benito Castro ${ }^{57}$, constituye un sujeto migrante y también se le identifica con un proyecto modernizador. Sin embargo, constituye un progreso distinto, porque ya no implica abandonar las creencias o «supersticiones»; constituye, por lo tanto, una modernización alternativa que, lamentablemente, no se concreta en la novela. Al igual que el proyecto escolar en la comunidad de Rumi, ese progreso se identifica con un proyecto futuro; por esa razón, la muerte de Rendón se manifiesta «como si un río subterráneo empezara su creciente» ${ }^{58}$.

\section{Conclusiones}

Como ya se ha demostrado, el mito del progreso se manifiesta tanto en El mundo es ancho y ajeno como en Todas las sangres, ya que en ambas la escuela y la migración constituyen temas que se vinculan a la modernización de la zona andina. Sin embargo, es evidente que, en las novelas, esos temas se plantean de manera diferente y adquieren también distinta importancia dentro de la trama. Probablemente, eso se debe a la fecha de publicación de los textos: en la novela de Ciro Alegría, que se publicó en 1941, se privilegia el mito de la escuela, ya que en la década de 1930 aún se discutía las implicancias de la Ley Orgánica de Enseñanza (1920). Esta ley indicaba que educación primaria era obligatoria para toda la población, intensificaba la enseñanza del castellano y prohibía el empleo de textos en quechua. En cambio, en la novela de Arguedas, el tema de la migración se desarrolla más ampliamente, ya que se publicó de forma posterior a la gran migración andina a Lima (década de 1950).

Por otro lado, el progreso (entendido igualmente como modernización) es también planteado de formas distintas. Especialmente en El mundo es ancho y ajeno es fácil reconocer que la escuela y el sujeto migrante corresponden a un proyecto cuyo objetivo es desterrar las creencias y las supersticiones (lo tradicional) de una comunidad. Constituye, por lo tanto, el tipo de modernización que Carlos Iván Degrégori criticó: «[...] la modernidad es vista como el tránsito entre una sociedad tradicional y una moderna, de una manera lineal o excluyente: o se es tradicional o se es moderno; para ser moderno hay que abandonar todas las características tradicionales» ${ }^{59}$. Esta característica es más notable si recordamos que se

57 Escajadillo ya había intuido estos vínculos entre los dos protagonistas: «Tal es el caso, por ejemplo, de la similitud de los "aprendizajes limeños" de Benito Castro y Demetrio Rendón Willka, personajes que cumplen una misma función de liderazgo comunal en sus respectivos orbes novelísticos» (1977: 138).

58 Arguedas 2001: 604.

59 Degregori 2013: 299. 
plantea que la comunidad es el único lugar donde el campesino puede ser feliz. En cambio, en Todas las sangres el proceso se muestra mucho más complejo y contradictorio; de esta forma, se deja entrever que la modernización no implica necesariamente abandonar lo tradicional. Por el contrario, una característica fundamental del libro de Arguedas es proponer una suerte de manifiesto del sujeto migrante, una esperanza de modernidad andina. 


\section{REFERENCIAS BIBLIOGRÁFICAS}

ALEGRÍA, Ciro (2002). El mundo es ancho y ajeno. Lima: Peisa.

ARGUEDAS, José María (2001). Todas las sangres. Lima: Peisa.

ANSIÓN, Juan (1993). «El mito de la escuela hoy». Consultado el 10 de febrero de 2014 de http://www.cholonautas.edu.pe/modulo/upload/Ansion\%201.pdf

CORNEJO POLAR, Antonio (1995). «Condición migrante e intertextualidad multicultural: el caso de Arguedas». En Revista de Crítica Literaria Latinoamericana, año XXI, nro. 42, pp. 101-109.

ESCAJADILLO, Tomás G. (1977). «Trayectoria y sentido de la peripecia de los comuneros emigrados en El mundo es ancho y ajeno». En San Marcos, nro. 18, pp. $90-146$.

(1978). «El símbolo de la construcción de la escuela en El mundo es ancho y ajeno». En Runa. Revista del Instituto Nacional de Cultura, nro. 7-8, pp. 24-28.

ESPEZÚA SALMÓN, Dorian (2007). Científicos sociales versus críticos literarios (Todas las sangres en debate). Tesis para obtener el grado académico de Magíster en Literatura Peruana y Latinoamericana. Universidad Nacional Mayor de San Marcos.

DEGREGORI, Carlos Iván (1991). «Educación y mundo andino». Consultado el 10 de febrero de 2014 de http://www.cholonautas.edu.pe/modulo/ upload/cid2.pdf

(2013a). «Del mito de Inkarrí al mito del progreso». En Del mito de Inkarrí al mito del progreso. Migración y cambios culturales. Lima: Instituto de Estudios Peruanos.

(2013b). «Dimensión cultural de la experiencia migratoria». En Del mito de Inkarrí al mito del progreso. Migración y cambios culturales. Lima: Instituto de Estudios Peruanos.

GOLTE, Jürgen (2001). Cultura, racionalidad y migración andina. Lima: Instituto de Estudios Peruanos.

LÓPEZ ALBÚJAR, Enrique (1987). «Sobre la psicología del indio». En Manuel Aquézolo Castro (compilador). La polémica del indigenismo. Lima: Mosca Azul Editores.

MONTOYA, Rodrigo (1990). «La escuela y el mito civilizatorio de Occidente». En Por una educación bilingüe en el Perú. Reflexiones sobre cultura y socialismo. Lima: Centro Peruano de Estudios Sociales y Mosca Azul Editores.

NORIEGA, Julio (1997). «La poética quechua del migrante andino». En Revista de Crítica Literaria Latinoamericana, año XXIII, nro. 46, pp. 53-65. 
OLIART, Patricia (1984). «Migrantes andinos en un contexto urbano: Las cholas en Lima». En Debates en Sociología, nro. 10, pp. 69-93.

TRIGO, Abril (1997). «Migrancia: memoria: modernidá». En Mabel Moraña (editora). Ángel Rama y los estudios latinoamericanos. Pittsburg: Instituto Internacional de Literatura Iberoamericana. 